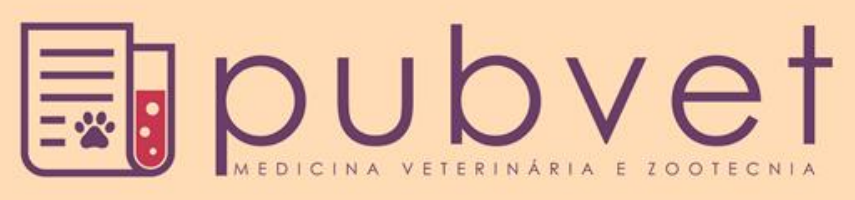

https://doi.org/10.31533/pubvet.v12n8a152.1-6

\title{
Leishmaniose canina na cidade de Caucaia, Ceará: Relato de Caso
}

\author{
Karina dos Santos Rodrigues ${ }^{1}$, Aline Maia Silva ${ }^{2}$, Anderson Pinto de Almeida ${ }^{2}$, \\ Michelle Costa e Silva ${ }^{2}$, Daniel de Araujo Viana ${ }^{3}$, Alain da Silva Durans Barreto ${ }^{\circ}$ \\ ${ }^{I}$ Graduanda em Medicina Veterinária pela Faculdade Terra Nordeste, Caucaia, Ceará, Brasil. \\ ${ }^{2}$ Docente do Curso de Medicina Veterinária da Faculdade Terra Nordeste, Caucaia, Ceará, Brasil. \\ ${ }^{3}$ Médico Veterinário, Doutor em Biotecnologia da Saúde pela RENORBIO/UECE, Fortaleza, Ceará, Brasil. \\ ${ }^{4}$ Médico Veterinário, graduado pela Faculdade Terra Nordeste, Caucaia, Ceará, Brasil. \\ *Autor para correspondência, E-mail: karina.dsr@hotmail.com
}

\begin{abstract}
RESUMO. As leishmanioses são zoonoses de grande importância, consequentes do parasitismo por protozoários intracelulares do gênero Leishmania, da família dos Trypanosomatidae. Transmitidas através da picada de insetos dípteros hematófagos pertencentes à subfamília Phlebotominae, tendo o cão como principal reservatório urbano. Duas formas clínicas são conhecidas: a leishmaniose visceral caracterizada por alterações sistêmicas e por vezes cutâneas, e a tegumentar, que podem produzir manifestações com lesões mucocutâneas, formação de úlceras de fundo granulomatoso e bordas salientes de difícil cicatrização. O objetivo deste trabalho foi relatar um caso de um canino, sem raça definida, macho, de 10 anos de idade, que foi atendido com histórico de ulceração em focinho, pavilhão auricular e língua, com manifestações clínicas agravando desde 2009. A realização do exame histopatológico foi determinante para a visualização de formas amastigotas de Leishmania spp, sendo possível o diagnóstico de leishmaniose.
\end{abstract}

Palavras chave: Cão, histopatológico, úlcera, dermatite piogranulomatosa

\section{Canine Leishmaniasis in the city of Caucaia, Ceará: Case Report}

\begin{abstract}
Leishmaniasis is a major zoonosis, resulting from the parasitism by intracellular protozoa of the Leishmania genus of the Trypanosomatidae family. It is transmitted through the bite of hematophagous dipterous insects belonging to the subfamily Phlebotominae, with the dog as the main urban reservoir. Two clinical forms are known: visceral leishmaniasis characterized by systemic and sometimes cutaneous alterations, and tegumentary, which can produce manifestations with mucocutaneous lesions, formation of granulomatous background ulcers and protruding edges of difficult healing. The objective of this research was to report a case of a 10-year-old dog male with no defined race, who was treated with a history of ulceration in the nose, ear and tongue, with clinical manifestations aggravating since 2009. The histopathological examination was determinant for the visualization of amastigote forms of Leishmania spp, being possible the diagnosis of leishmaniasis.
\end{abstract}

Keywords: Dog, histopathological, ulcer, pyogranulomatous dermatites

\section{Leishmaniosis canina en la ciudad de Caucaia, Ceará: Reporte de un caso}

RESUMEN. Las leishmaniosis son zoonosis de gran importancia, consecuentes del parasitismo por protozoos intracelular del género Leishmania, de la familia de los Trypanosomatidae, es transmitida a través de la picada de insectos dípteros hematófagos pertenecientes a la subfamília Phlebotominae, teniendo el perro como principal reservatorio urbano. Dos formas clínicas son conocidas: la leishmaniosis visceral caracterizada por alteraciones sistémicas y por veces cutáneas, y la tegumentaria, que 
pueden producir manifestaciones con lesiones mucocutáneas, formación de úlceras de fondo granulomatoso y bordes salientes de difícil cicatrización. El objetivo de este trabajo fue reportar el caso clínico de un perro, sin raza definida, macho, de 10 años de edad, que fue atendido con histórico de ulceración en el hocico, pabellón auditivo y lengua, con manifestaciones clínicas agravando desde 2009. La realización del examen histopatológico fue determinante para la visualización de formas amastigotes de Leishmania spp, siendo posible el diagnóstico de leishmaniosis.

Palabras clave: Perro, histopatológico, úlcera, dermatitis piogranulomatosa

\section{Introdução}

As leishmanioses têm distribuição mundial e atingem 88 países, sendo 72 destes países em desenvolvimento (Desjeux, 2004). De caráter zoonótico, essas doenças constituem problemas de saúde pública, sendo responsáveis por altas taxas de mortalidade e morbidade, principalmente em áreas rurais (Lonardoni et al., 2006). No Brasil é considerada uma doença re-emergente e em franca expansão, atualmente com o crescimento dos centros urbanos $\mathrm{e}$ as dificuldades socioeconômicas, a leishmaniose não está mais confinada às regiões florestais ocorrendo também nas periferias e nos grandes centros urbanos (Jesus \& Araújo, 2007). São doenças crônicas, de manifestação tegumentar ou visceral, causadas por protozoários flagelados do gênero Leishmania, pertencente à família Trypanosomatidae (Gontijo et al., 2011; Grandi et al., 2014) são digenéticos e apresentam duas formas evolutivas: uma flagelada denominada promastigota, que é encontrada no tubo digestivo do inseto vetor e em alguns meios de cultura artificiais, e a outra forma é ovalada denominada de amastigota, que é intracelular obrigatória, sendo encontrada nas células do sistema fagocitário dos hospedeiros vertebrados (Gontijo \& Carvalho, 2003; Gontijo et al., 2011). A principal forma de transmissão do parasita para o homem e outros hospedeiros mamíferos é vetorial, através do repasto sanguíneo das fêmeas de dípteros da família Psychodidae, sub família Phebotominae, gênero Lutzomya, conhecidos genericamente por flebotomíneos (Gontijo \& Carvalho, 2003). Várias ordens de mamíferos, incluindo Edentata, Carnivora, Hyracoidea, Rodentia, Primatas, Marsupialia e Peris-sodactyla são considerados hospedeiros da Leishmania sp. (Lima et al., 2016). No ciclo de transmissão, os cães são frequentemente infectados por esse parasita e são considerados como os reservatórios primários na região peridomiciliar (Dantas-Torres et al., 2017), sendo o principal reservatório doméstico da Leishmaniose Visceral Humana (LVH), causada por Leishmania infantum, além disso, também podem ser infectados por
Leishmania (Leishmania) amazonenses e Leishmania (Viannia) braziliensis causando a Leishmaniose Tegumentar Americana (LTA) (Gontijo et al., 2011; Lima et al., 2016).

A LTA é uma doença caracterizada por lesões de pele, cartilagem e mucosas. A forma de apresentação clínica varia, tanto em humanos como em animais, conforme a espécie de Leishmania envolvida e sua interação com o seu hospedeiro (Hoffmann et al., 2012). Na espécie canina, a forma tegumentar se manifesta com lesões mucocutâneas, formação de úlceras de fundo granulomatoso e bordas salientes de difícil cicatrização nas regiões de orelhas, focinho ou bolsa escrotal (Lima et al., 2016).

Como não existe um teste diagnóstico que apresente $100 \%$ de especificidade e sensibilidade para tal doença, a confirmação do diagnóstico deve se basear na associação da avaliação clínica com técnicas parasitológicas, sorológicas e moleculares (Leontides et al., 2002). Exames laboratoriais para a pesquisa do parasita em fluidos e tecidos pela avaliação do conteúdo aspirado, ou imprint feito com o fragmento da biópsia para exame histopatológico são métodos bastante utilizados (Ciaramella \& Corona, 2003). As técnicas recomendadas atualmente pelo Ministério da Saúde para o inquérito sorológico canino são a de imuno-florescência indireta (RIFI) e o método de imuno-ensaio enzimático (ELISA). A reação em cadeia de polimerase (PCR) tem sido usada para identificar e amplificar seletivamente sequências de DNA do parasito, a principal desvantagem das técnicas moleculares é que estas requerem laboratórios bem equipados e habilidade técnica (Hoffmann et al., 2012).

O objetivo deste trabalho foi relatar a presença de Leishmania spp. em exame histopatológico de um canino domiciliado.

\section{Material e Métodos}

Um canino, macho, sem raça definida, 10 anos de idade e pesando $8,850 \mathrm{~kg}$, vacinado (Canigen ${ }^{\circledR}$ V8 e Canigen ${ }^{\circledR} \mathrm{R}$ ) e com vermifugação em dias, 
foi atendido na Policlínica Veterinária Metropolitana - HVM no município de Caucaia $\mathrm{CE}$, com a queixa principal de lesões de caráter ulcerativo e desfigurante em septo nasal e pavilhão auricular esquerdo, com presença de intenso prurido.

$\mathrm{Na}$ anamnese a tutora do animal relatou que essas manifestações clínicas começaram no ano de 2009 , com uma pequena lesão na ponta do focinho e foi agravando com o tempo e acometendo outras partes do corpo do animal. Já havia levado o animal em outras clínicas veterinárias, realizado protocolos terapêuticos não obtendo bons resultados, e exames complementares, tais como: três punções de medula nos anos de 2009, 2011 e 2014 e sorologia para leishmaniose no ano de 2016, obtendo resultados negativos de ambos exames. Segundo a mesma, não foram observadas alterações do apetite, dos hábitos intestinais e de micção.

No exame clínico, foram observadas mucosas normocoradas, linfonodos palpáveis, temperatura corpórea de $39,4^{\circ} \mathrm{C}$, lesões com caráter ulcerativo e desfigurantes em septo nasal, pavilhão auricular esquerdo e língua (Figura 1), descamação cutânea furfurácea e onicrogrifose. Foi solicitado exame hematológico, creatinina e alanina aminotransferase - ALT, para monitorização da condição de saúde do animal, além do exame histopatológico das lesões e punção de linfonodo por punção aspirativa por agulha fina, para diferenciar processos infecciosos de neoplásicos. Realizou-se ainda PCR qualitativo para Leishmania spp.

Para o exame hematológico foi coletado $5,0 \mathrm{~mL}$

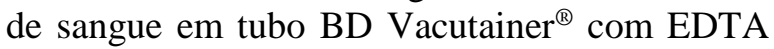
através da venopunção da jugular. Para a coleta de espécimes clínicos, o animal foi submetido à sedação com diazepam na dose de $0,5 \mathrm{mg} / \mathrm{kg}$ e associação de cetamina na dose de $10 \mathrm{mg} / \mathrm{kg}$ por via intravenosa, após o protocolo anestésico foi realizada biópsia de pele do pavilhão auricular e do focinho para realização do exame histopatológico. O material obtido da citologia foi disposto sobre lâminas de vidro por meio de squash, em seguida foram corados em panótico rápido e avaliados em microscopia óptica no aumento de 100x. Já para a PCR qualitativa de Leishmania spp. coletou-se $3 \mathrm{~mL}$ de sangue em tubo BD Vacutainer ${ }^{\circledR}$ com EDTA por venopunção da jugular, conservado em caixa isotérmica com gelo seco durante o transporte e em geladeira até a extração do DNA. Os testes foram realizados em duplicata, com dois controles positivos e dois controles negativos.

Até a obtenção dos resultados o paciente foi medicado com cefalexina (30 mg/kg/VO/BID) e prednisona (20 $\mathrm{mg} / \mathrm{kg} / \mathrm{VO} / \mathrm{BID})$, devido as infecções dermatológicas e intenso prurido do animal.
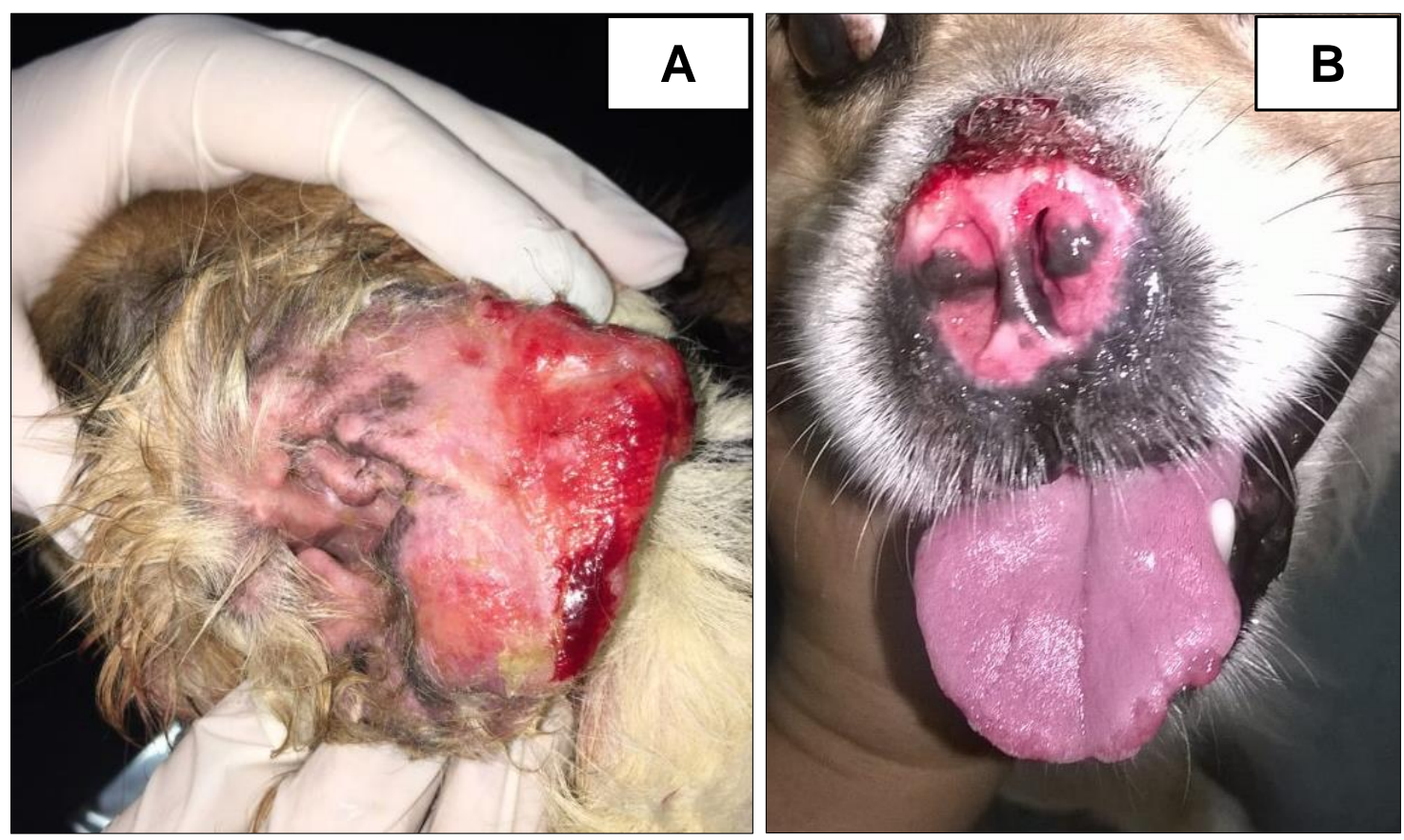

Figura 1. Canino acometido com lesões tegumentares em pavilhão auricular esquerdo (A), septo nasal e língua (B), provocadas por Leishmania spp. Fonte: Policlínica Veterinária Metropolitana - HVM. 


\section{Resultados e Discussão}

O hemograma revelou uma discreta hiperproteinemia, uma leucocitose com eosinofilia e monocitose (Tabela 1), enquanto que os exames bioquímicos se mantiveram dentro dos limites da normalidade (Tabela 2). Os principais achados laboratoriais da leishmaniose tegumentar americana canina incluem anemia, geralmente normocítica normocrômica, hiperproteinemia, hiperglobulinemia, trombocitopenia, leucocitose e eosinofilia (Queiroz et al., 2010), o animal atendido possuía alterações hematológicas compatíveis para sugerir a suspeita da doença.

No exame citopatológico foi observado uma eosinofilia de moderada a acentuada nos tecidos linfoides, exibindo uma anisocitose moderada, com citoplasma escasso, núcleo central, amplo e com cromatina frouxa (Figura 2). A citologia aspirativa é um método amplamente utilizado no diagnóstico da leishmaniose, possibilita a observação das formas amastigotas da Leishmania $s p p$. pela punção aspirativa de linfonodo e medula óssea. Quando não se evidenciam as formas amastigotas em uma amostra citológica, a chance de um resultado falso negativo é considerável. Sendo assim, o diagnostico deve ser baseado na celularidade obtida sugerindo então, qual a real possibilidade de o paciente ser, ou não, hospedeiro do protozoário, pois dependo da fase de instalação do processo, a infecção por Leishmania spp. pode promover uma eosinofilia de moderada a acentuada nos tecidos linfoides (Grandi et al., $\underline{2014)}$.

No exame histopatológico foram visualizadas formas amastigotas de Leishmania spp. no citoplasma de macrófagos, sendo conclusivo para dermatite piogranulomatosa consequente à infecção pelo parasito (Figura 3). Foi realizado o método molecular PCR, que teve resultado conclusivo para Leishmania sp. Após a análise dos resultados laboratoriais o animal foi encaminhado para outra clínica veterinária, onde é realizado o tratamento de animais com leishmaniose.

Apesar de ser uma zoonose originalmente silvestre, a LTA tem sido assinalada em ambientes antrópicos de áreas endêmicas, onde há a possibilidade de animais domésticos, como o cão, serem reservatórios (Lonardoni et al., 2006). É uma doença com diversidade de agentes etiológicos, de reservatórios, de vetores, diferentes padrões de transmissão e um conhecimento ainda limitado sobre alguns aspectos, o que a torna de difícil controle ( $\underline{\text { FNS, 2010) }}$.

A importância da LTA no contexto da saúde pública vem aumentando devido à modificação de suas características epidemiológicas. Ocorre de forma endêmico-epidêmica apresentando diferentes padrões de transmissão, relacionados não somente à penetração do homem em focos silvestres o que sugere a possível adaptação dos vetores a ambientes modificados e reservatórios.

Tabela 1. Resultado de eritrograma e do leucograma realizados em canino que apresentava lesões tegumentares ulcerativas no pavilhão auricular esquerdo, plano nasal e língua (Coleta 15/09/17)

\begin{tabular}{lcc}
\hline Parâmetros & Resultado & Referências - espécie canina \\
\hline Eritrograma & $6,2(\mathrm{milhões} / \mathrm{mm} 3)$ & $5.500 .000-8.500 .000 / \mathrm{mm}^{3}$ \\
Eritrócitos & $14,5 \mathrm{~g} / \mathrm{dL}$ & $12-18(\mathrm{~g} / \mathrm{dL})$ \\
Hemoglobina & $43 \%$ & $37-55(\%)$ \\
Volume Globular & $69,3 \mathrm{fL}$ & $60-77(\mathrm{fL})$ \\
VGM & $33,7 \%$ & $32-36(\%)$ \\
CHGM & $220(\mathrm{mil} / \mathrm{mm} 3)$ & $200.000-500.000 / \mathrm{mm} 3$ \\
Plaquetas & 8,4 & $6.0-8.0(\mathrm{~g} / \mathrm{dL})$ \\
Proteína Total & $18,0(\mathrm{mil} / \mathrm{mm} 3)$ & \\
\hline Leucograma & $60 / 10,800$ & $6.000-17.000 / \mathrm{mm} 3$ \\
Leucócitos & $9 / 1,620$ & $300-11.500 / \mathrm{mm} 3$ \\
Segmentados & $13 / 2,340$ & $1.000-4.800 / \mathrm{mm} 3$ \\
Linfócitos & $18 / 3,240$ & $100-1.250 / \mathrm{mm} 3$ \\
Eosinófilos & Hemácias: rouleaux eritrocitário. Leucócitos: sem alterações & $150-1.350 / \mathrm{mm} 3$ \\
Monócitosológicas. Plaquetas: sem
\end{tabular}

Fonte: Laboratório de Patologia Clínica HVM - 2017. 
$\mathrm{O}$ vetor tende a adaptar-se às condições observadas em áreas peridomésticas, principalmente em razão do acúmulo de matéria orgânica gerada por animais domésticos e más condições sanitárias (Gontijo \& Carvalho, 2003; FNS, 2010).

Tabela 2. Resultados dos exames bioquímicos realizados em canino que apresentava lesões tegumentares ulcerativas no pavilhão auricular, plano nasal e língua.

\begin{tabular}{l|cc}
\hline Bioquímicos & Resultado & Referência \\
\hline ALT (TGP) & $38 \mathrm{U} / \mathrm{I}$ & $-<50(\mathrm{U} / \mathrm{I})$ \\
Creatinina & $1,0 \mathrm{mg} / \mathrm{dL}$ & $0,5-1,5(\mathrm{mg} / \mathrm{dL})$ \\
\hline
\end{tabular}

Fonte: Laboratório de Patologia Clínica HVM - 2017.

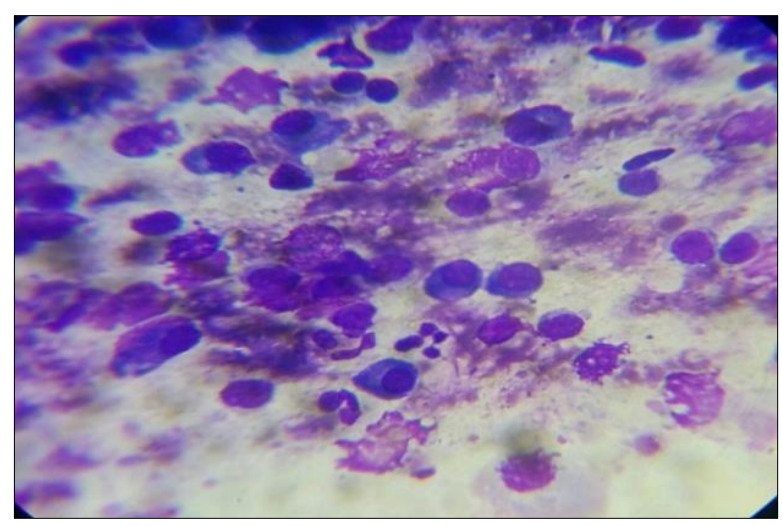

Figura 2. Citologia de amostra obtida por punção aspirativa por agulha fina de linfonodo de um cão com Leishmaniose Tegumentar Americana, apresentando uma eosinofilia de moderada a acentuada. Fonte: Laboratório de Patologia Clínica HVM (2017).
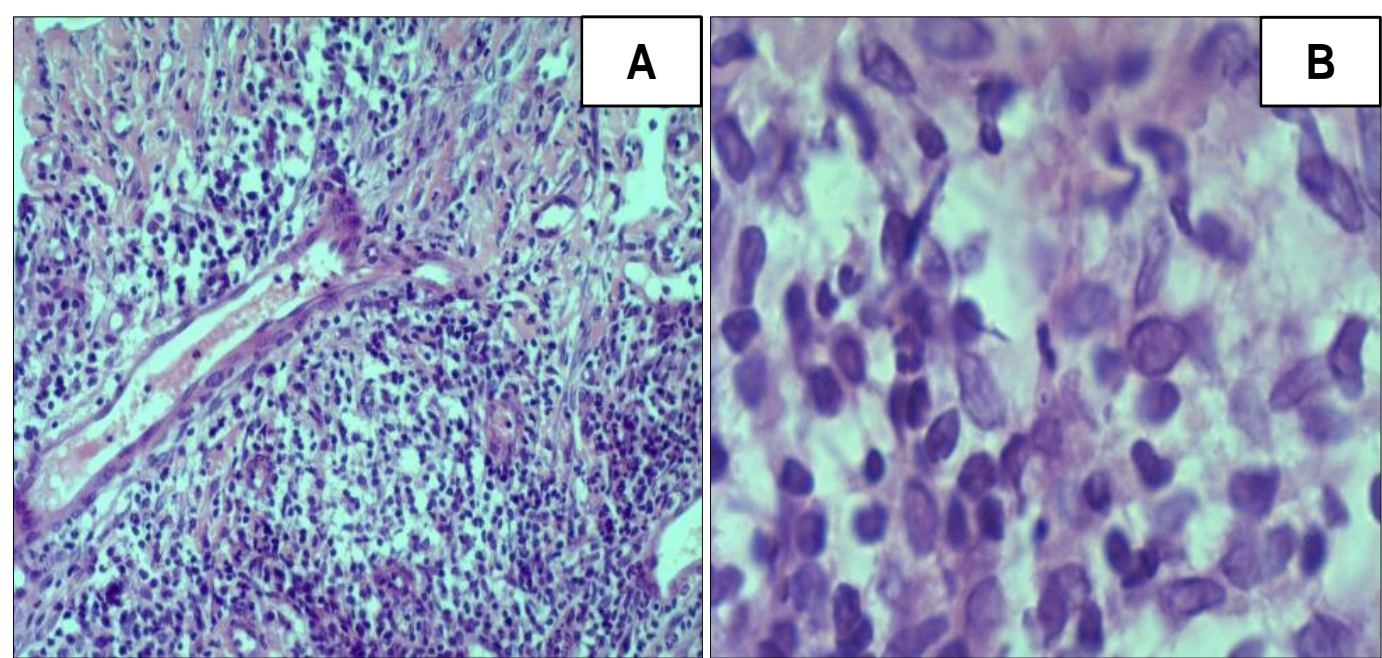

Figura 3. Lâmina histopatológica da epiderme, apresentando hiperplasia pseudoepiteliomatosa com áreas ulceradas por intenso processo inflamatório (A), com algumas formas amastigotas de Leishmania spp (B). Fonte: PATHOVET - Anatomia Patológica e Patologia Clínica Veterinária (2017).

São aproximadamente 350 milhões de pessoas em risco e 12 milhões de casos, com incidência anual mundial estimada de 0,7 a 1,2 milhões de casos de leishmaniose tegumentar (LT) e de 0,2 a 0,4 milhões de casos de leishmaniose visceral (LV). O Brasil ocupa posição de destaque como um dos países com maior produção de casos de LT e LV. Segundo o Ministério da Saúde no período de 1990 a 2016 foram notificados 687.780 casos de LT, com autoctonia de transmissão em todos os estados, sendo a Região Norte-Nordeste do país a que apresenta maior índice de casos (FNS, 2010). Porém, com os movimentos migratórios das populações dessas regiões em direção ao sul do país, a doença se expandiu, a partir da década de 80, para todo o território nacional, tornando-se grande problema de saúde pública (Jesus \& Araújo, 2007).

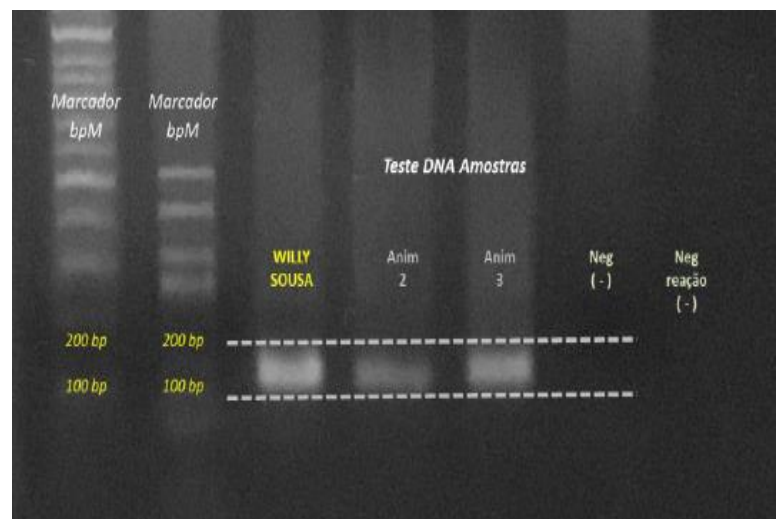

Figura 4. Amostra do resultado qualitativo obtido através da técnica Reação em Cadeia da Polimerase (Polimerase Chain Reaction - PCR), baseada na amplificação de segmentos específicos de DNA leishmanial, apresentando 99,9\% de sensibilidade e especificidade. Fonte: On Cells Biotechnology, Unidade de Pesquisa e Transferência Biotecnológica - UPTBI. 
O diagnóstico da leishmaniose é complicado pela patologia da doença. Apesar de discordância entre alguns autores, o exame parasitológico é considerado, ainda o teste ouro para o diagnóstico da leishmaniose, podendo ser observadas formas amastigotas do parasito em esfregaços sanguíneos e de linfonodo, medula óssea, aspirado esplênico, swab conjuntival e exame histopatológico. Atualmente, a sorologia para a detecção de anticorpos é uma ferramenta de diagnóstico valiosa para a infecção por $L$. infantum, devido aos altos níveis de anticorpos induzidos, que difere das infecções por L. amazonensis e L. braziliensis que produzem níveis mais baixos de anticorpos (Lima et al., 2016).

Conclui-se com este trabalho que é imprescindível que em pacientes com lesões cutâneas persistentes seja realizada análise histopatológica para o diagnóstico diferencial de Leishmaniose, principalmente em regiões endêmicas, nas quais o número de casos de Leishmaniose tende a crescer nas áreas domesticas e peridomicilares. Apesar da dificuldade de diagnóstico, a rapidez na realização de vários testes diagnósticos é de extrema importância, visto que permite a adoção de medidas preventivas, evitando que o animal se torne um possível reservatório doméstico, obtendo-se consequentemente maior sucesso no combate da leishmaniose.

\section{Referências Bibliográficas}

Ciaramella, P., Corona, M., 2003. Canine leishmaniasis: clinical and diagnostic aspects. Compeindium on Continuing Education for the Practising Veterinarina-North American Edition 25, 358-369.

Dantas-Torres, F., Sales, K.G.S., Silva, L.G., Otranto, D., Figueredo, L.A., 2017. LeishmaniaFAST15: a rapid, sensitive and low-cost realtime PCR assay for the detection of Leishmania infantum and Leishmania braziliensis kinetoplast DNA in canine blood samples. Molecular and Cellular Probes 31, 65-69.

Desjeux, P., 2004. Leishmaniasis: current situation and new perspectives. Comparative immunology, microbiology and infectious diseases 27, 305-318.

FNS, 2010. - Fundação Nacional de Saúde. Ministério da Saúde.

Gontijo, B., Carvalho, M.L.R., 2003. Leishmaniose tegumentar americana. Revista da Sociedade Brasileira de Medicina Tropical 36, 71-80.
Gontijo, B.B., Pavão, F.F., Silva, F.S.A., Silva, F.D., Tavares, G.C., Coelho, G.L., 2011. Esporotricose e Leishmaniose Tegumentar em cães e gatos: semelhanças e diferenças. PUBVET 5, 1245-1250.

Grandi, F., Beserra, H.E.O., Costa, L.D., 2014. Citopatologia Veterinária Diagnóstica. Editora MedVet, São Paulo, Brasil.

Hoffmann, A.R., Navarro, I.T., Camargo Junior, V.E., Caldart, E.T., Breganó, R.M., Pereira, P.M., 2012. Leishmania amazonensis em cão com quadro clínico de leishmaniose visceral no Estado do Paraná, Brasil - relato de caso. Semina: Ciências Agrárias 33, 3265-3270.

Jesus, J.R., Araújo, F.A.P., 2007. Leishmaniose tegumentar americana: uma visão da epidemiologia da doença na Região Sul. Clínica Veterinária 12, 82-84.

Leontides, L.S., Saridomichelakis, M.N., Billinis, C., Kontos, V., Koutinas, A.F., Galatos, A.D., Mylonakis, M.E., 2002. A cross-sectional study of Leishmania spp. infection in clinically healthy dogs with polymerase chain reaction and serology in Greece. Veterinary Parasitology 109, 19-27.

Lima, B.S.S., Fialho Júnior, L.C., Pires, S.F., Tafuri, W.L., Andrade, H.M., 2016. Immunoproteomic and bioinformatic approaches to identify secreted Leishmania amazonensis, L. braziliensis, and L. infantum proteins with specific reactivity using canine serum. Veterinary Parasitology 223, 115-119.

Lonardoni, M.V.C., Silveira, T.G.V., Alves, W.A., Maia-Elkhoury, A.N.S., Membrive, U.A., Membrive, N.A., Rodrigues, G., Reis, N., Zanzarini, P.D., Ishikawa, E., 2006. Leishmaniose tegumentar americana humana e canina no Município de Mariluz, Estado do Paraná, Brasil. Cadernos de Saúde Pública 22, 2713-2716.

Queiroz, N., Assis, J.d., Oliveira, T., Machado, R.Z., Nunes, C.M., Starke-Buzetti, W.A., 2010. Diagnóstico da Leishmaniose Visceral Canina pelas técnicas de imunoistoquímica e PCR em tecidos cutâneos em associação com a RIFI e ELISA-teste. Revista Brasileira de Parasitologia Veterinária 19, 32-38.

Recebido: 14 Jun., 2018

Aprovado: 26 Jul., 2018

Publicado: 9 Ago., 2018

Licenciamento: Este artigo é publicado na modalidade Acesso Aberto sob a licença Creative Commons Atribuição 4.0 (CC-BY 4.0), a qual permite uso irrestrito, distribuição, reprodução em qualquer meio, desde que o autor e a fonte sejam devidamente creditados. 